\title{
Digital platform ecosystems
}

\section{Andreas Hein $^{1} \cdot$ Maximilian Schreieck $^{1} \cdot$ Tobias Riasanow $^{1} \cdot$ David Soto Setzke $^{1} \cdot$ Manuel Wiesche $^{2} \cdot$ Markus Böhm $^{1}$. Helmut Krcmar ${ }^{1}$}

Published online: 12 November 2019

(C) The Author(s) 2019

\begin{abstract}
Digital platforms are an omnipresent phenomenon that challenges incumbents by changing how we consume and provide digital products and services. Whereas traditional firms create value within the boundaries of a company or a supply chain, digital platforms utilize an ecosystem of autonomous agents to co-create value. Scholars from various disciplines, such as economics, technology management, and information systems have taken different perspectives on digital platform ecosystems. In this Fundamentals article, we first synthesize research on digital platforms and digital platform ecosystems to provide a definition that integrates both concepts. Second, we use this definition to explain how different digital platform ecosystems vary according to three core building blocks: (1) platform ownership, (2) value-creating mechanisms, and (3) complementor autonomy. We conclude by giving an outlook on four overarching research areas that connect the building blocks: (1) technical properties and value creation; (2) complementor interaction with the ecosystem; (3) value capture; and (4) the make-or-join decision in digital platform ecosystems.
\end{abstract}

Keywords Digital platform $\cdot$ Platform ecosystems $\cdot$ Governance $\cdot$ Openness $\cdot$ Ownership

JEL classification D4 $\cdot \mathrm{D} 15 \cdot \mathrm{O} 3$

\section{Introduction}

Regarding its digital platform ecosystems with more than 13,000 partners, the software company SAP stated, "reaching our full potential depends on how well we enable our partners, providing them with [the] tools they need to accelerate growth and exceed customer expectations in an increasingly complex world." (SAP Partner Edge 2017). Digital platforms as technical infrastructures and their ecosystems of social actors continue to change entire

Responsible Editor: Hans-Dieter Zimmermann

Andreas Hein

andreas.hein@tum.de

Maximilian Schreieck

maximilian.schreieck@tum.de

Tobias Riasanow

tobias.riasanow@tum.de

David Soto Setzke

setzke@tum.de

Manuel Wiesche

manuel.wiesche@tu-dortmund.de industries. Airbnb lists over 4 million accommodations, more than the top five hotel brands combined (Hartmans 2017). Uber has a network of 7 million drivers, overshadowing local taxi companies (Dogtiev 2017). Facebook coordinates 2 billion active users each month (Constine 2017), vastly outnumbering newspaper subscriptions. All of those digital platforms build on the widespread availability of constantly evolving information technology, such as cloud computing, in-memory databases, and analytical solutions for big data.

Markus Böhm

markus.boehm@tum.de

Helmut Krcmar

krcmar@tum.de

1 Chair for Information Systems, Technical University of Munich, Boltzmannstr. 3, 85748 Garching bei München, Germany

2 Technische Universität Dortmund, Martin-Schmeißer-Weg 12, 44227 Dortmund, Germany 
Digital platforms combine and deploy these technologies in new ways to incubate and coordinate an ecosystem of supply and demand (Hein et al. 2019a). In the ecosystem, actors on the demand side take the role of complementors by cocreating complementary products or services (e.g., Lucas and Goh 2009; Alt et al. 2010). Complementors use boundary resources, such as software development kits (SDK) provided by the platform owner (Ghazawneh and Henfridsson 2013), to co-create specialized products or services (Boudreau 2012). Customers are the beneficiaries and remunerate these services through payments or by providing data and feedback. The platform owner can incorporate this feedback to increase the quality of existing services and tap into new markets (Eisenmann et al. 2011).

Although digital platforms are an omnipresent phenomenon, scholars from various disciplines have adopted different perspectives. This Fundamentals article synthesizes the literature of digital platforms and ecosystems in combination with contemporary examples of digital platform ecosystems to develop a novel research model. The research model helps to characterize and analyze different digital platform ecosystems. Based on this synthesis, we suggest that three attributes are essential when discussing the different variants of digital platform ecosystems: (1) platform ownership, (2) value-creating mechanisms, and (3) the autonomy of complementors. We conclude this article by providing an outlook on four overarching research areas.

\section{Background and definitions}

The scholarly field of digital platform ecosystems is broad and diverse. Scholars from various disciplines take different perspectives on how digital platforms orchestrate an ecosystem of actors to co-create value (Lusch and Nambisan 2015). These disciplines include economics with a market-based perspective (Parker et al. 2017; McIntyre and Srinivasan 2017), technology management with a technical perspective (Tiwana et al. 2010; Baldwin and Woodard 2009; Tilson et al. 2010), and information systems with a socio-technical perspective (de Reuver et al. 2018; Constantinides et al. 2018). Additionally, more recent articles have emphasized the dedicated perspective of ecosystems as a fruitful basis for new theories on sustaining competitive advantage (Adner 2017; Jacobides et al. 2018; Kapoor 2018).

\section{Digital platforms}

The market-based perspective goes back to the work of Rochet and Tirole (2003), who studied market power in the presence of network externalities (Schilling 2002; Katz and Shapiro 1986). Network externalities describe how the value for one side of the market increases as the number of actors on the other side increases (Schilling 2002). However, placing a higher value on products or services with a vast installed-base of actors presents challenges and offers new opportunities for companies to leverage network effects (McIntyre and Srinivasan 2017). One particular challenge for emerging digital platforms is the chicken-and-egg problem: the platform needs both the complementor and the consumer side to ensure a valid value proposition, but neither side is willing to join as long as the other side is not populated (Caillaud and Jullien 2003). Another factor that influences the performance of digital platforms is the multi-homing behavior of users by reducing the exclusivity and dominant-firm equilibria (Koh and Fichman 2014; Caillaud and Jullien 2003). Digital platforms with a sufficient installed base - so-called platform leaderscan use their dominant position in the market to increase their market share even further (Gawer and Cusumano 2014). Strategies include platform envelopment, adopted for example by Amazon, that used its profits to tap into new markets by subsidizing cloud-computing services or by using its information superiority to out-compete internal complementors (Zhu and Liu 2018). Other examples are antitrust cases, such as those against Microsoft and Google (Iacobucci and Ducci 2019; Schmalensee 2000) that show the relevance and importance of the so-called "winner-take-all" effect of two-sided markets (Cennamo and Santalo 2013).

The technical perspective sees digital platforms as softwarebased platforms, that is, extensible codebases that provide core functionality, supplemented by modular services (Tiwana et al. 2010; Tilson et al. 2010). Each modular service is a software subsystem that can extend the functionality of the platform (Baldwin and Woodard 2009). Examples for modular services can be SDKs that the platform owner provides or value-adding complements from complementors. Those complementors can use standardized interfaces such as application programming interfaces (API) to integrate new modules (Ghazawneh and Henfridsson 2013; Hein et al. 2019b). The standardized integration process and modular architecture of software-based platforms minimize interdependencies among modules and foster network externalities by reducing translation costs between different modules (Farrell and Saloner 1985; Katz and Shapiro 1994). Thus, the software-based platform is not only a source of economies of scale and scope (Thomas et al. 2014); it also fosters economies of substitution (Garud and Kumaraswamy 1995). Economies of substitution result from reusing modular and upgradable components in a platform instead of designing a system from scratch (Garud and Kumaraswamy 1993). The modularity of a software-based platform makes it easier for both external complementors and the platform owner to substitute system components while retaining a stable core. In turn, upgradability enables both parties to work on already-established modules that preserve the platform's knowledge base (Wheelwright and Clark 1992; Foerderer et al. 2019). In summary, the stability of the software-based platform and boundary resources ensures that complementors can develop and integrate modules without 
extensive knowledge of platform architectures, whereas the modular architecture allows for versatility and scalability of new modules (Tiwana et al. 2010).

Apart from the modular and architectural views on digital platforms, scholars draw on the innovation capabilities of digital infrastructures (Tilson et al. 2010; Yoo et al. 2012; Constantinides et al. 2018), wherein a crucial characteristic is the provision of digital affordances (Tan et al. 2016; Nambisan et al. 2019). Digital affordances refer to "what an individual or organization with a particular purpose can do with a technology" (Majchrzak and Markus 2013). To provide new affordances, the digital infrastructure builds upon a modular software-based platform that is inherently malleable, meaning it can be reconfigured to adapt user needs and prompt new technological advances (Yoo et al. 2010; Hein et al. 2019a). The platform owner provides affordances via boundary resources, such as SDKs, that assist complementors in cultivating products or services on top of a software-based platform (Constantinides et al. 2018; Hein et al. 2019b). An example is Apple's introduction of the augmented reality kit (ARKit) that extends the iOS platform and provides new affordances to all third-party developers.

The socio-technical perspective focuses on how platform owners integrate and govern an ecosystem of actors (de Reuver et al. 2018). A particular governance mechanism is the provision of boundary resources that takes the form of interfaces, such as APIs, or toolkits, such as SDKs, to integrate and enable an ecosystem of actors to co-create complementary products or services (Ghazawneh and Henfridsson 2013). Interfaces represent standardized processes, whereas toolkits provide a shared worldview by strengthening the interpretative flexibility between actors of the ecosystem and the digital platform (Lusch and Nambisan 2015; Hein et al. 2019b). Depending on the openness of interfaces, the platform owner can restrict the ecosystem to internal use within the company, for example, to enterprise resource planning systems or can open the ecosystem to take advantage of the innovation capabilities of external complementors that provide value-adding services. The degree of openness also influences competition within and across ecosystems (Gawer 2014; Thomas et al. 2014). Depending on the archetype of ownership, either a central platform owner, a consortium of partners or a decentralized peer-to-peer network need to balance control rights against the autonomy of ecosystem actors (de Reuver et al. 2018; Ghazawneh and Henfridsson 2013). The ownership status influences the evolutionary dynamics of an ecosystem by changing how governance mechanisms such as input and output control, and decision rights are implemented (Tiwana et al. 2010; Tiwana 2014; Hein et al. 2016). Consequently, research on digital platforms has emphasized the need to focus on boundaries between digital platforms and their ecosystem (Foerderer et al. 2019; Karhu et al. 2018).

\section{Digital platform ecosystems}

The latest conceptual work on ecosystems ${ }^{1}$ (Kapoor 2018; Adner 2017; Jacobides et al. 2018) shows the rise of a new research paradigm. Up to now, digital platforms have been mainly analyzed from single paradigms such as economics (Jiang et al. 2018), technical (Tiwana 2015), business (Parker and Van Alstyne 2017), and social (Thies et al. 2016). Whereas the literature on boundary resources only combines the social and technical paradigms (Eaton et al. 2015), we suggest a paradigm shift by integrating the intraorganizational technical perspectives on digital platforms and the inter-organizational economic, business, and social perspectives on ecosystems. In this new paradigm, digital platforms rely heavily on autonomous agents that contribute to the digital platform's value proposition (Teece 2018). This core tenet highlights the need for digital platforms to enable and coordinate an ecosystem of actors while being exposed to interdependencies. The interdependencies between platform and agents in an ecosystem can have both economic and structural components (Kapoor 2018; Adner 2017).

Economic components describe the type of complementarities of products or services provided by complementors. Jacobides et al. (2018) focused on unique and supermodular complementarities to characterize the relationship between a platform and actors in an ecosystem. In a unique complementarity, Product A does not function without Product B. More generally, the value of Product A is maximized with Product B. Additionally, the complementarity can be one-way. Thus, Product A requires a particular Product or Service B. It can also be two-way. Thus, Products A and B both require each other (Teece 1986). In a supermodular complementarity, an increased amount of Product A makes Product B more valuable, where A and $B$ are different products or services. The ecosystem of application stores illustrates the effect of unique and supermodular complementarities. The applications and the application store have unique complementarity in the sense that the applications cannot function without the store and its underlying platform. Furthermore, a supermodular complementarity exists because the presence of applications increases the value of the store (Jacobides et al. 2018).

Another fundamental characteristic of an ecosystem is its generativity (Henfridsson and Bygstad 2013; Yoo et al. 2010), where generativity is defined as the "overall capacity to produce unprompted changes driven by large, varied, and uncoordinated audiences" (Zittrain 2005). Building on the digital affordances provided by the platform owner, ecosystem actors fuel generativity with individual innovation capabilities

\footnotetext{
${ }^{1}$ The term, "ecosystems," originated from biological systems of interacting organisms that are placed in a habitat. Moore (1993) established this concept in the business literature. The idea was taken up by Iansiti and Levien (2004) to describe mutual dependencies of actors in business ecosystems.
} 
(Nambisan et al. 2019). For example, complementors can share their knowledge to come up with new ideas of valueadding complements, in turn, fueling the generativity of the ecosystem (Dokko et al. 2014). Another example stems from the application development industry, where more external complementors on a digital platform lead to more variety and more applications (Boudreau 2012).

The structural components in an ecosystem describe how actors interact with value proposition and value creation. Recent studies have focused on three structural elements of ecosystems: activities, actors, and architectures (Kapoor 2018; Adner 2017).

Activities are discrete actions that determine how value is co-created in an ecosystem. Activities in a digital platform ecosystem include the development of new applications or the provision of services, such as offering rides or listing new properties. Objects of inquiry include bottlenecks that result from the interdependencies of actors and products in an ecosystem. Bottlenecks are critical components whose performance, costs, and scarcity constrain the value proposition of an ecosystem (Kapoor 2018). Research on digital platforms has suggested that platforms act as bottlenecks to control and limit interactions in an ecosystem (Boudreau 2010).

Actors are agents that can take the role of complementors and consumers who undertake activities and produce different offers. First, complementors provide complementary products or services to contribute to a platform's value proposition. It is important to note that the role of the complementor differs from that of traditional firm-supplier relationships. Whereas the complementor autonomously decides to join an ecosystem, in a firm-supplier relationship, the firm exerts decision rights regarding the cooperation (Kapoor 2018). Second, consumers refer to service beneficiaries that, in turn, contribute to the platform's value proposition by providing insights about how and which complements are used (Lusch and Nambisan 2015).

The architecture defines technological interactions that orchestrate the exchange between the supply and demand sides of an ecosystem. This architecture can result in either a platform- or product-based ecosystem (Kapoor 2018). Platform-based ecosystems contain autonomous agents, such as complementors, that contribute complementary products or services. Depending on the ownership status of platforms, the platform owners establish governance mechanisms that define the ground rules for orchestrating interactions in the ecosystems (Gawer and Cusumano 2002; Tiwana 2014). For example, Uber facilitates the interactions between drivers and passengers. In contrast, product-based ecosystems entail onesided market interactions between a firm and consumers (Kapoor 2018). For example, the mobility service provider, DriveNow, owns the complementary products (cars) and merely integrates consumers as service beneficiaries.

Summarizing research on digital platforms and ecosystems, we conclude that digital platforms are built on a modular architecture comprising a stable core and a flexible periphery
(Tiwana et al. 2010), taking advantage of economies of scale and substitution (Garud and Kumaraswamy 1995; Thomas et al. 2014). With platform governance mechanisms, the platform owner facilitates transactions between autonomous complementors and consumers in an ecosystem (Lusch and Nambisan 2015; de Reuver et al. 2018). Above the modular infrastructure, the platform owner provides affordances that complementors can actualize based on individual innovation capabilities. Besides, complementors can interact with each other to utilize the generativity of the digital platform ecosystem (Yoo et al. 2012; Nambisan et al. 2019). Based on this synthesis, we propose the following definition:

a digital platform ecosystem comprises a platform owner that implements governance mechanisms to facilitate valuecreating mechanisms on a digital platform between the platform owner and an ecosystem of autonomous complementors and consumers.

\section{Three building blocks of digital platform ecosystems}

Applying the definition on established and emerging digital platform ecosystems, we conclude three different building blocks to characterize digital platform ecosystems: status of platform ownership; value-creating mechanisms in the ecosystem; and autonomy of complementors (Fig. 1). In this section, we outline the three building blocks and their characteristics based on variations from well-known digital platform ecosystems.

\section{Platform ownership}

Platform ownership is an essential factor for the design and governance of digital platform ecosystems (Bakos and Katsamakas 2008; Tiwana et al. 2010). Platform ownership is not just about the legal entity that owns the digital platform; it also relates to the distribution of power in the ecosystem, which can be centralized or decentralized. It also describes the relationships among partners in the ecosystem. We found different ownership models that depend on the degree of power centralization and classified them into three main archetypes.

First, there are centralized digital platform ecosystems controlled by a single owner, such as Facebook, the Apple iOS mobile operating system, and the SAP Cloud Platform. In this case, power is centralized, and only the platform owner as a single entity defines, establishes, and maintains governance mechanisms. Thus, the platform owner can implement and adjust governance mechanisms quickly and in a way that is best for ecosystem growth. However, with a growing ecosystem, some digital platforms have come to dominate their markets, such as Google and Apple: the mobile operating system market. In such cases, the centralized power of the platform owner becomes overwhelming. For example, platform owners can exclude 
Fig. 1 Building blocks and characteristics of digital platform ecosystems

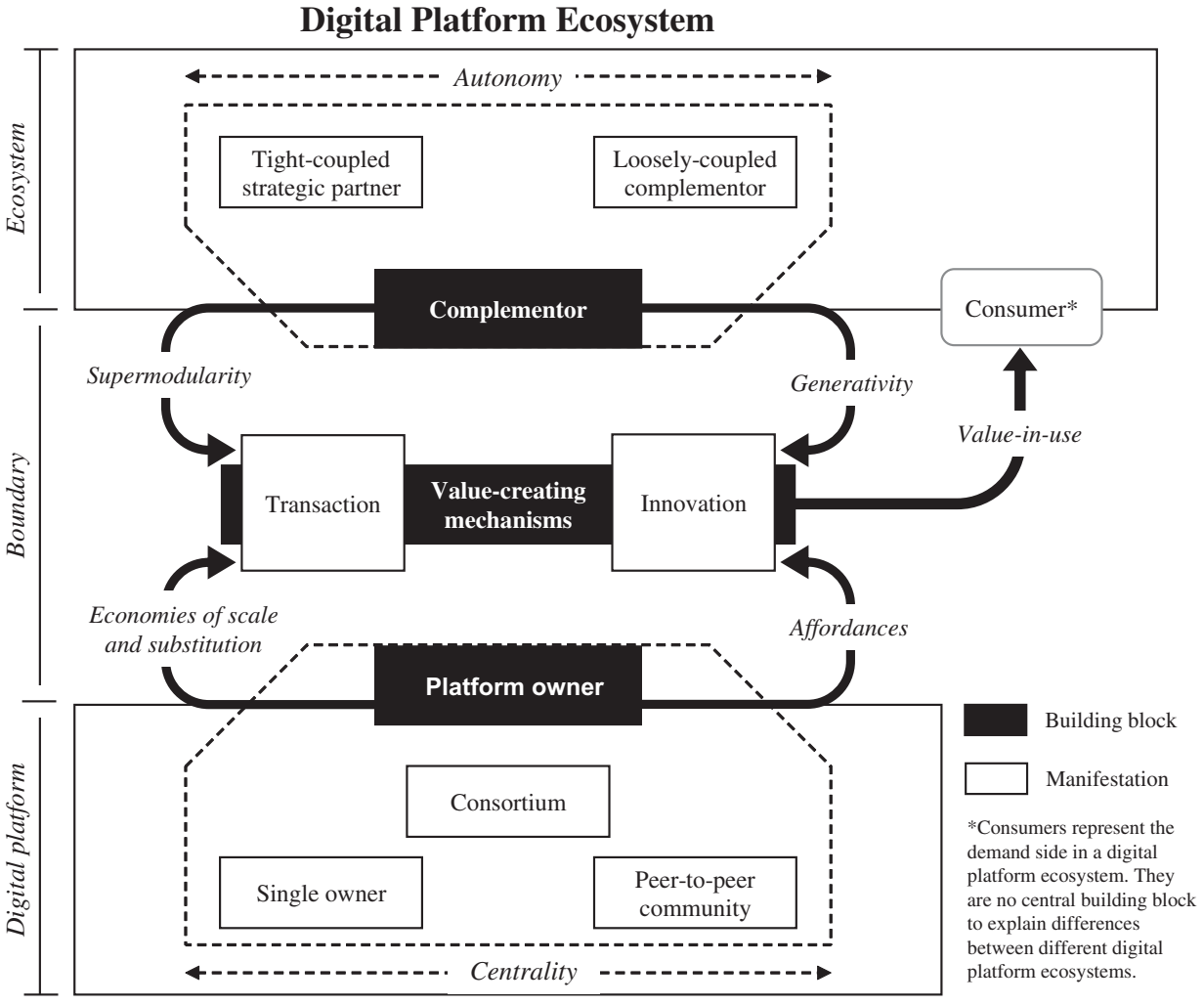

complementors from their platforms or limit collaboration with hardware partners, such as Google did in 2019 with device manufacturer Huawei (Satariano et al. 2019).

Second, digital platform ecosystems can be formed by consortia, implying that a group of actors owns the digital platform and, thus, establishes the governance mechanisms (Bazarhanova et al. 2019). An example of this ownership archetype is the Cloud Foundry, an open-source, multi-cloud application platform-as-a-service governed by the Cloud Foundry Foundation. In contrast to centralized digital platform ecosystems, consortia typically imply a distribution of power over multiple stakeholders. These stakeholders jointly define, establish, and maintain governance mechanisms for the digital platform ecosystem. In the Cloud Foundry Foundation, actors, such as Cisco, SAP, Dell EMC, IBM, Pivotal, SUSE, and VMware, jointly support the management of the platform ecosystem.

Third, there are decentralized digital platform ecosystems governed by peer-to-peer communities. Blockchain platforms, such as Ethereum or District0x, allow the creation of decentralized ecosystems that can be governed by a community (Riasanow et al. 2018a). This decentralization empowers users to directly influence the future direction of the ecosystem. For instance, District0x offers a digital platform that allows users to design and establish new marketplaces in the form of districts. As users stake tokens to a project, they gain voting rights. These rights can be used to participate in design changes and functionality improvements of a district and to specify how the generated revenue of a marketplace is used or distributed (Lestan et al. 2017).

\section{Platform value-creating mechanisms}

Successful digital platforms facilitate value-creating mechanisms in the platform ecosystem. These value-creating mechanisms build on the efficient and convenient facilitation of transactions (Tiwana 2014) and the provision of affordances making the digital platform a breeding ground for innovation (Yoo et al. 2012).

With the first value-creating mechanism of transactions, digital platforms help complementors and consumers locate and interact with each other and exchange value in a mutually beneficial manner (Evans 2012). The digital platform acts as an intermediary by directly matching supply to demand and suggesting possible transactions or by providing easy-to-use search functions through which users can find transaction partners. Via the orchestration of transactions, digital platforms create two-sided markets (Armstrong 2006; Rochet and Tirole 2003) that leverage cross-side network effects. For example, Airbnb is a digital platform that facilitates transactions between property owners and people looking for temporary accommodations. The digital platform helps owners advertise their accommodations and offers a fine-tuned search functionality for users looking for a place to stay. Each new 
listing utilizes economies of scale and substitution and increases the value of the platform, making it a supermodular complementarity that induces network effects between supply and demand. Thus, individuals across the globe who would never have initiated such a transaction are brought together via the combined value of all listings on the Airbnb platform (Hartmans 2017). The basis for this value-creating mechanism is a modular software-based platform, where the platform owner provides value-creating services, such as payment functionalities or recommender systems to increase the efficiency and convenience of the services for the ecosystem (Hein et al. 2019a).

The second value-creating mechanism refers to the innovation capabilities of digital platforms that enable complementors to create solutions complementary to the platform core (Tiwana 2014). The platform owner provides affordances by offering development tools for complementors, who, in turn, can use those boundary resources to co-create value-adding complements (Ghazawneh and Henfridsson 2013; Nambisan et al. 2019). For example, SAP leverages third-party innovation on its SAP Cloud Platform (Schreieck et al. 2019). The digital platform offers affordances through APIs and other resources for complementors to create applications that complement SAP's enterprise resource planning software. The SouthAfrican SAP partner, EPI-USE, developed an application based on the platform's internet-of-things capabilities to monitor endangered species using drones. The nonprofit organization, Elephants, Rhinos \& Peoples, uses this application to obtain better information about the number of endangered animals (SAP SE 2018).

Similar to Elephants, Rhinos \& People, many other complementors utilize the generativity of SAP's offerings, because third parties often have specialized knowledge and experience, leading to knowledge transfer and better solutions. Customers can choose from these innovative complementary applications when adapting the enterprise resource planning software to their own needs or developing applications for their use.

Additionally, the generativity of the ecosystem can spoil new affordances that can be used by the platform owner. After establishing its ridesharing platform, Uber used its broad ecosystem to build additional services, such as UberEats, effectively enveloping and tapping into new markets.

\section{Complementor autonomy}

The autonomy of complementors describes the degree of freedom complementors have when co-creating value with the digital platform (Ye and Kankanhalli 2018). Complementors with a high autonomy are loosely coupled to the digital platform and contribute to the variety and amount of complements (Boudreau 2012). In turn, complementors with a low autonomy are tightly coupled to a digital platform and form strategic partnerships that strengthen the core focal-value proposition (Danneels 2003). Depending on the autonomy of complementors, the platform owner must cope with varying levels of control, scalability, and flexibility (Parker and Van Alstyne 2017).

High autonomy complementors refer to a loosely coupled relationship in which the complementor is independent and separate from the digital platform (Orton and Weick 1990). The complementor can either be an actor that actively contributes to the digital platform or another platform that is compatible but not actively engaged in the digital platform. An example of the former includes complementors of Airbnb, where homeowners have relatively low entrance barriers and can easily multi-home between different platforms. Autonomous platform-toplatform relationships can be illustrated in the case of Facebook, where other platforms can implement features, such as the "like" button. Although platform owners cannot exert direct control over high autonomy complementors, they can use the design of boundary resources to channel the interpretative flexibility of complementors to specify the design process of complements (Lusch and Nambisan 2015). An example includes SDKs, which help complementors develop complements by providing them with guidance and boilerplate code (Hein et al. 2019b; Foerderer et al. 2019).

Low-autonomy complementors refer to tightly coupled strategic partners in which both the platform owner and the complementor are mutually dependent and aligned (Orton and Weick 1990). Again, low-autonomy complementors can be individual actors or other platforms. An example of tightly coupled actors is the Open Handheld Alliance (OHA), used to promote and develop the Android operating system and to jointly compete against other mobile platforms, such as from Apple and Microsoft. Low-autonomy platform-to-platform relationships describe core dependencies and contributions to focal-value propositions such as Netflix that strongly relies on the Amazon Web Services infrastructure, despite having competing video-on-demand services (Butler 2013). Compared to high-autonomy relationships, tightly coupled partnerships are determined by high mutual trust, a commonly defined goal, and contracts (Steensma and Corley 2000) that define whether parties are allowed to provide their services to competing platforms.

It is important to note that digital platforms can build upon both high- and low-autonomy complementors. Taking Android as an example, they incorporate value-adding complements in the form of applications from a large amount of highly autonomous application developers while also sustaining low-autonomy relationships in the OHA to improve the core operating system. 


\section{Research outlook}

We recommend that future research on digital platform ecosystems considers the intersection between the internal digital platform and the platform owner, the external ecosystem and the autonomous complementors, and the intermediate perspective of value-creating mechanisms in the ecosystem. Combining different perspectives and the three building blocks provides holistic insights and actionable recommendations for theory and practice. In particular, we suggest investigating four novel avenues (see Table 1):

\section{Technical properties and value creation}

The first avenue for future research aims to reveal on how the platform owner can influence the value-creating mechanisms in the digital platform ecosystem. Prior information system studies on digital platform ecosystems primarily focused on economic aspects and advanced our understanding of topics, including organizational design (Ondrus et al. 2015) and market mechanisms (Lee 2013). To better understand the success factors of digital platform ecosystems, it is useful to examine their underlying technical properties (Tilson et al. 2010) and how those properties influence the co-creation of value with the ecosystem (de Reuver et al. 2018). Whereas the simple model of a platform as a stable core with a flexible periphery helps us understand the fundamental mechanisms of digital platforms, it does not illustrate the complexity of digital platforms that have emerged in recent years such as in the case of Taobao.com (Xie et al. 2018).

Table 1 Fruitful avenues for future research in digital platform ecosystems
Although we know that the efficient and convenient orchestration of transactions between supply and demand is a core mechanism of digital platforms (Gawer 2014; Thomas et al. 2014), it remains unclear how the IT artifact maintains a stable core and flexible periphery of modular complements. When observing the release history of iOS, significant updates are deployed each year, introducing new features, that can substitute complementary services, and boundary resources, such as ARKit (Costello 2019), that provide affordances to an ecosystem of complementors. This example illustrates how the software-based platform is subject to frequent changes at its stable core. However, it is unclear how, when, or why the stable core is altered to introduce new features, and what external information leads to the enhancement of the digital platform. Fruitful areas of future research range from investigating core IT artifacts, such as microservice architectures (Balalaie et al. 2016) and the relationship between infrastructure and supermodular complements (Tiwana 2018), work practices such as DevOps (Ebert et al. 2016; Wiedemann et al. 2019) that maintain and accelerate economies of substitution, and the utilization of customer data to determine which additional resources the platform owner needs to deploy to fuel the generativity of the ecosystem.

Another avenue of future research is the digital platform's technical innovation capabilities (Tilson et al. 2010; Yoo et al. 2012; Henfridsson and Bygstad 2013). We know that platform owners use boundary resources as standardized forms to enable a wide variety of complementors (Hein et al. 2019b; Ghazawneh and Henfridsson 2013) to develop many various complements (Boudreau 2012) fostering economies of scope.

\begin{tabular}{|c|c|}
\hline Avenue & Immediate future research questions \\
\hline $\begin{array}{l}\text { Technical properties and value } \\
\text { creation }\end{array}$ & $\begin{array}{l}\text { - When, why, and how is the stable core altered to introduce new } \\
\text { affordances? } \\
\text { - How does the platform owner balance the standardization and } \\
\text { interpretative flexibility of boundary objects? }\end{array}$ \\
\hline $\begin{array}{l}\text { Value capture in digital platform } \\
\text { ecosystems }\end{array}$ & $\begin{array}{l}\text { - What is the ideal degree of value capture in different competitive } \\
\text { situations and lifecycle stages of a digital platform? } \\
\text { - At what point do additional investments in platform architecture and } \\
\text { governance no longer pay off in terms of value capture? } \\
\text { - How is value shared in a platform ecosystem owned by a consortium or a } \\
\text { peer-to-peer community? }\end{array}$ \\
\hline $\begin{array}{l}\text { Complementor interaction with the } \\
\text { ecosystem }\end{array}$ & $\begin{array}{l}\text { - How do different types of complementors interact with the digital } \\
\text { platform to increase generativity? } \\
\text { - How can complementors in ecosystems influence the strategic decisions } \\
\text { of owners of digital platforms? }\end{array}$ \\
\hline $\begin{array}{l}\text { Make-or-join decision in digital } \\
\text { platform ecosystems }\end{array}$ & $\begin{array}{l}\text {-When and how should firms establish a new digital platform ecosystem? } \\
\text { When and how should firms join an existing digital platform } \\
\text { ecosystem? } \\
\text { - Which technical, economic, and ecosystem capabilities do platform } \\
\text { - How do we motivate complementors to join, grow, stay, and engage in } \\
\text { the digital platform ecosystem? }\end{array}$ \\
\hline
\end{tabular}


However, standardizing boundary resources too much could reduce the affordances provided by limiting the flexibility of complementors to come up with creative, out-of-the-box solutions (Foerderer et al. 2014). Hence, the platform owner must carefully balance the standardization of boundary resources to enable easy adoption in combination with the flexibility provided to use the innovation capabilities of individual complementors. By understanding this tradeoff, we can elaborate what measures platform owners can take to control the generativity of a digital platform ecosystem by either reducing entrance barriers to a variety of complementors through standardization or by granting flexibility to come up with innovative complements.

\section{Value capture in digital platform ecosystems}

The second avenue for future research aims to indicate how the platform owner and the autonomous complementors capture value in digital platform ecosystems. Recent research on digital platforms has predominantly aimed to explain how platform owners and complementors interact in the digital platform ecosystem to create value. We summarized this as value-adding mechanisms for transaction and innovation. The question of how the value is distributed among the platform owner and complementors, that is, who captures what share of the value, remains mostly unanswered (Helfat and Hall 2018).

To better understand the value a platform owner can capture, it is crucial to analyze their position to claim value and their costs associated with governing the ecosystem. For example, a platform owner who dominates a market can claim a higher share of the value than a platform owner new to a market. Simultaneously, creating economies of scale and substitution and providing affordances require investments in the platform's architecture and boundary resources.

Considerations of value capture must go beyond pricing and revenue-sharing mechanisms (Hagiu 2006; Tiwana 2014; Oh et al. 2015). Scholars have already suggested that the absorption of complementary solutions (Parker et al. 2017; Eisenmann et al. 2009) and investments in selected complementary products (Rietveld et al. 2016) are further mechanisms capturing value from a digital platform ecosystem. Building on that knowledge, it would be worthwhile to study the ideal degree of value capture in different competitive situations and lifecycle stages of a digital platform. The ideal degree of value capture might also differ for different levels of autonomy that complementors are granted. Furthermore, we raise the question of at what point additional investments in platform architecture and governance no longer pay off in terms of value capture. For example, maintaining and updating resources, such as an SDK for third-party developers, is costly and needs to be considered when calculating the value captured from third-party innovation in the ecosystem. Lastly, value sharing and thus, value capture, differs across ownership archetypes. Even the definition of what is perceived as value might differ, because participation in a consortium can be based on motives other than monetary, such as gaining insights into technological advances or being visible within an industry.

\section{Complementor interaction with ecosystem}

The third avenue for future research aims to shed light on how the autonomous complementors in a digital platform ecosystem can influence value-creating mechanisms. The scientific research on the autonomy of complementors in digital platform ecosystems has focused mainly on the platform-owner perspective and the paradox of balancing control and openness (Boudreau 2012; Tiwana et al. 2010). The platform owner can either use the design of boundary resources (Ghazawneh and Henfridsson 2013; Eaton et al. 2015) or governance mechanisms, including defining decision rights and review processes (Tiwana 2014; Song et al. 2018) to balance control and openness. However, we still know little about how complementors as a level of analysis can influence the creation of value in a digital platform ecosystem (Selander et al. 2013) or even how the generativity of an ecosystem can influence the digital platform (Adner 2017).

Taking the complementor as a level of analysis, we know that different states of complementor motivation can influence the performance of digital platforms (Chen et al. 2018) and that complementors cross-pollinate from a variety of different ecosystems to increase the generativity of the digital platform ecosystem (Selander et al. 2013). Apart from notable exceptions (Ye and Kankanhalli 2018), it remains unclear how different types of high and low autonomy complementors interact with the digital platform to provide new affordances and increase the generativity of the digital platform ecosystem. Shifting the object of inquiry to complementors allows us to shed light on their work processes, their adoption processes, and their development of platform-specific capabilities. We seek to understand how complementors can shape the future direction of the digital platform. An example is the growing discontent of Uber drivers who protest for better working conditions. They are attempting to impose changes in governance mechanisms implemented by the platform owner (Conger et al. 2019).

The ecosystem perspective primarily deals with the impact of network effects (Song et al. 2018; Parker et al. 2017) or how the digital platform can fuel or constrain the focal-value proposition of an ecosystem (Kapoor 2018; Kapoor and Agarwal 2017). However, as shown in the example of striking complementors in the case of Uber (Conger et al. 2019), complementors can also influence the strategic decisions of digital platform ecosystems. The same interdependencies can be observed at the ecosystem level, where not only the platform owner can provide affordances to the ecosystem, but the ecosystem can also generate affordances that the platform owner can actualize. Taking Uber as an example, 
the company first established an efficient infrastructure that orchestrates interactions between drivers and passengers and then recognized that this ecosystem could also be used to provide additional services, such as UberEats. Those interdependencies give rise to novel questions, such as how the structure of ecosystems can influence strategic decisions of platform owners. Zhu and Iansiti (2019), for example, showed that local clusters of supply and demand in the case of Uber provided less (supermodular) value to the digital platform compared to global clusters in the case of Airbnb. A consequence is that less-dense ecosystem structures are more prone to multi-homing effects.

\section{Make-or-join decision in digital platform ecosystems}

Last, the fourth avenue for future research spans across all three building blocks and covers the perspective of incumbent firms that find themselves confronted with the decision of whether to establish a new digital platform ecosystem or join an existing one. Recent examples can be found in various industries, ranging from mobility-service platforms (Frahm 2019) to additive manufacturing (EOS GmbH 2019). In the former case, both Daimler and BMW created product-based platforms and joined forces by merging into a consortiumbased mobility platform ecosystem. In the latter case, EOS, an additive manufacturing company, established a new digital production ecosystem.

Despite notable exceptions (Sebastian et al. 2017), we know relatively little about how incumbents transition toward digital platform ecosystems and what challenges arise during their transformations (Hein et al. 2019a; de Reuver et al. 2018). It is unclear why and how firms should establish a digital platform. Organizations can develop a platform on their own, as a consortium of industry partners, or as a peer-to-peer platform ecosystem. Additionally, we suggest future research to uncover the technical, economic, and ecosystem capabilities needed to build a digital platform ecosystem (Tan et al. 2016). First, technical capabilities deal with how firms transform their legacy system toward a digital infrastructure capable of fostering economies of scale and substitution and digital affordances. Second, economic capabilities deal with how the firm can innovate their business model from a one-sided to a two-sided business model where they can still capture sufficient value. Third, from an ecosystem perspective, it is pivotal to understand how firms can integrate their existing network of stakeholders from a goods-dominant perspective of creating value to a services-dominant perspective of co-creating value (Lusch and Nambisan 2015). Thus, incumbents can apply platform governance mechanisms used in digital platform ecosystems, but they must adapt them to the specific situations related to their existing network of stakeholders. Additionally, firms must align those capabilities to define the core functionalities of their digital platform and determine what is left for complementary services building on the modular architecture of the digital platform (Tiwana et al. 2010; Ghazawneh and Henfridsson 2013).

Based on technical or economic reasons, the decision may also be to join an existing digital platform ecosystem. First, a thorough analysis of the ecosystem is helpful to identify the roles of the actors (Riasanow et al. 2018b). Organizations should also understand value creation in the ecosystem (Urmetzer et al. 2018). Based on the assessment and the analysis of their own technical and economic capabilities, organizations can identify suitable roles in the ecosystem. However, this can depend on the ownership structure and the technical architecture of the digital platform. For example, some services may not be feasible to provide, or they are already covered by the digital platform owner and architecture.

Acknowledgments We would like to thank the editor, Hans-Dieter Zimmermann, and anonymous reviewers whose insightful comments helped to advance the development of this paper throughout the review process.

Open Access This article is distributed under the terms of the Creative Commons Attribution 4.0 International License (http:// creativecommons.org/licenses/by/4.0/), which permits unrestricted use, distribution, and reproduction in any medium, provided you give appropriate credit to the original author(s) and the source, provide a link to the Creative Commons license, and indicate if changes were made.

\section{References}

Adner, R. (2017). Ecosystem as structure: An actionable construct for strategy. Journal of Management, 43(1), 39-58.

Alt, R., Abramowicz, W., \& Demirkan, H. (2010). Service-orientation in electronic markets. Electronic Markets, 20(3), 177-180.

Armstrong, M. (2006). Competition in two-sided markets. RAND Journal of Economics, 37(3), 668-691.

Bakos, Y., \& Katsamakas, E. (2008). Design and ownership of two-sided networks: Implications for internet platforms. Journal of Management Information Systems, 25(2), 171-202.

Balalaie, A., Heydarnoori, A., \& Jamshidi, P. (2016). Microservices architecture enables Devops: Migration to a cloud-native architecture. IEEE Software, 33(3), 42-52.

Baldwin, C. Y., \& Woodard, C. J. (2009). The architecture of platforms: A unified view. In A. Gawer (Ed.), Platforms, markets and innovation (pp. 19-44). Cheltenham: Edward Elgar Publishing.

Bazarhanova, A., Yli-Huumo, J., \& Smolander, K. (2019). From Platform Dominance to Weakened Ownership: How External Regulation Changed Finnish E-Identification. Electronic Markets (In print).

Boudreau, K. J. (2010). Open platform strategies and innovation: Granting access Vs. devolving control. Management Science, 56(10), 1849-1872.

Boudreau, K. J. (2012). Let a thousand flowers bloom? An early look at large numbers of software app developers and patterns of innovation. Organization Science, 23(5), 1409-1427.

Butler, B. (2013). Amazon and Netflix: Competitors Who Need Each Other. NetworkWorld, https://www.networkworld.com/article/ 2168433/amazon-andnetflix\% 2D\%2Dcompetitors-who-needeach-other.html. Accessed 01.04.2019. 
Caillaud, B., \& Jullien, B. (2003). Chicken \& egg: Competition among intermediation service providers. RAND Journal of Economics, 34(2), 309-328.

Cennamo, C., \& Santalo, J. (2013). Platform competition: Strategic tradeoffs in platform markets. Strategic Management Journal, 34(11), $1331-1350$

Chen, W., Wei, X., \& Zhu, K. X. (2018). Engaging voluntary contributions in online communities: A hidden Markov model. Management Information Systems Quarterly, 42(1), 83-100.

Conger, K., Xu, V. X., \& Wichter, Z. (2019). Uber Drivers' Day of Strikes Circles the Globe before the Company's I.P.O. The New York Times, https://www.nytimes.com/2019/05/08/technology/uber-strike.html . Accessed 01.06.2019. Times, https://www.nytimes.com/2019/05/ 08/technology/uber-strike.html. Accessed 01.06.2019.

Constantinides, P., Henfridsson, O., \& Parker, G. G. (2018). Introduction-Platforms and infrastructures in the digital age. Information Systems Research, 29(2), 381-400.

Constine, J. (2017). Facebook Now Has 2 Billion Monthly Users... and Responsibility. https://techcrunch.com/2017/06/27/facebook-2billion-users/. Accessed 01.12.2017.

Costello, S. (2019). The History of Ios, from Version 1.0 to 12.0. Lifewire, https://www.lifewire.com/ios-versions-4147730. Accessed 20.05. 2019.

Danneels, E. (2003). Tight-loose coupling with customers: The enactment of customer orientation. Strategic Management Journal, 24(6), 559-576.

de Reuver, M., Sørensen, C., \& Basole, R. C. (2018). The digital platform: A research agenda. Journal of Information Technology, 23(2), 124-135.

Dogtiev, A. (2017). Uber Revenue and Usage Statistics 2017. Business of Apps, https://www.businessofapps.com/data/uber-statistics/. Accessed 01.12.2017.

Dokko, G., Kane, A. A., \& Tortoriello, M. (2014). One of us or one of my friends: How social identity and tie strength shape the creative Generativity of boundary-spanning ties. Organization Studies, 35(5), 703-726.

Eaton, B., Elaluf-Calderwood, S., Sørensen, C., \& Yoo, Y. (2015). Distributed tuning of boundary resources: The case of Apple's Ios service system. MIS Quarterly, 39(1), 217-243.

Ebert, C., Gallardo, G., Hernantes, J., \& Serrano, N. (2016). Devops. IEEE Software, 33(3), 94-100.

Eisenmann, T. R., Parker, G., \& Van Alstyne, M. (2009). Opening platforms: How, when and why? In A. Gawer (Ed.), Platforms, markets and innovation (pp. 131-162). Cheltenham: Edward Elgar.

Eisenmann, T. R., Parker, G., \& Van Alstyne, M. (2011). Platform envelopment. Strategic Management Journal, 32(12), 1270-1285.

EOS GmbH (2019). 30 Years of Eos. EOS GmbH, https://www.eos.info/ 30-years-of-eos-84f2244fcd6652e5. Accessed 01.05.2019.

Evans, D. S. (2012). Governing bad behavior by users of multi-sided platforms. Berkeley Technology Law Journal, 2(27), 1201-1250.

Farrell, J., \& Saloner, G. (1985). Standardization, compatibility, and innovation. The Rand Journal of Economics, 16(1), 70-83.

Foerderer, J., Kude, T., Schuetz, S., \& Heinzl, A. (2014). Control Versus Generativity: A Complex Adaptive Systems Perspective on Platforms. In Proceedings of the International Conference on Information Systems. New Zealand: Auckland.

Foerderer, J., Kude, T., Schuetz, S. W., \& Heinzl, A. (2019). Knowledge boundaries in Enterprise software platform development: Antecedents and consequences for platform governance. Information Systems Journal, 29(1), 119-144.

Frahm, C. (2019). Was Man Zur Carsharing-Fusion Wissen Muss. Spiegel Online, https://www.spiegel.de/auto/aktuell/carsharingdaimler-und-bww-legencar2go-und-drive-now-zusammen-a1200573.html. Accessed 01.50.2019.

Garud, R., \& Kumaraswamy, A. (1993). Changing competitive dynamics in network industries: An exploration of sun Microsystems' open systems strategy. Strategic Management Journal, 14(5), 351-369.
Garud, R., \& Kumaraswamy, A. (1995). Technological and organizational designs for realizing economies of substitution. Strategic Management Journal, 16(1), 93-109.

Gawer, A. (2014). Bridging differing perspectives on technological platforms: Toward an integrative framework. Research Policy, 43(7), 1239-1249.

Gawer, A., \& Cusumano, M. A. (2002). Platform Leadership: How Intel, Microsoft, and Cisco Drive Industry Innovation (Vol. 5): Harvard Business School Press Boston, MA.

Gawer, A., \& Cusumano, M. A. (2014). Industry platforms and ecosystem innovation. Journal of Product Innovation Management, 31(3), 417-433.

Ghazawneh, A., \& Henfridsson, O. (2013). Balancing platform control and external contribution in third-party development: The boundary resources model. Information Systems Journal, 23(2), 173-192.

Hagiu, A. (2006). Pricing and commitment by two-sided platforms. The Rand Journal of Economics, 37(3), 720-737.

Hartmans, A. (2017). Airbnb Now Has More Listings Worldwide Than the Top Five Hotel Brands Combined. Business Insider, http://www. businessinsider.de/airbnb-total-worldwide-listings-2017-8?r= US\&IR=T. Accessed 01.12.2017.

Hein, A., Schreieck, M., Wiesche, M., Böhm, M., \& Krcmar, H. (2019a). The Emergence of Native Multi-Sided Platforms and Their Influence on Incumbents. Electronic Markets, (In print), 1-17.

Hein, A., Schreieck, M., Wiesche, M., \& Krcmar, H. (2016) MultipleCase Analysis on Governance Mechanisms of Multi-Sided Platforms. In Proceedings of the Multikonferenz Wirtschaftsinformatik, Ilmenau, Germany, (pp. 9-11).

Hein, A., Weking, J., Schreieck, M., Wiesche, M., Böhm, M., \& Krcmar, H. (2019b). Value Co-Creation Practices in Business-to-Business Platform Ecosystems. Electronic Markets, 29(3), 503-518.

Helfat, C. E., \& Hall, T. (2018). Dynamic and integrative capabilities for profiting from innovation in digital platform-based ecosystems. Research Policy, 47(8), 1391-1399.

Henfridsson, O., \& Bygstad, B. (2013). The generative mechanisms of digital infrastructure evolution. MIS Quarterly, 37(3), 907-931.

Iacobucci, E., \& Ducci, F. (2019). The Google search case in Europe: Tying and the single monopoly profit theorem in two-sided markets. European Journal of Law and Economics, 47(1), 15-42.

Iansiti, M., \& Levien, R. (2004). Strategy as ecology. Harvard Business Review, 82(3), 68-81.

Jacobides, M. G., Cennamo, C., \& Gawer, A. (2018). Towards a theory of ecosystems. Strategic Management Journal, 39(8), 2255-2276.

Jiang, Y., Ho, Y.-C., Yan, X., \& Tan, Y. (2018). Investor platform choice: Herding, platform attributes, and regulations. Journal of Management Information Systems, 35(1), 86-116.

Kapoor, R. (2018). Ecosystems: Broadening the locus of value creation. Journal of Organization Design, 7(1), 12.

Kapoor, R., \& Agarwal, S. (2017). Sustaining superior performance in business ecosystems: Evidence from application software developers in the Ios and android smartphone ecosystems. Organization Science, 28(3), 531-551.

Karhu, K., Gustafsson, R., \& Lyytinen, K. (2018). Exploiting and defending open digital platforms with boundary resources: Android's five platform forks. Information Systems Research, 29(2), 479-497.

Katz, M. L., \& Shapiro, C. (1986). Technology adoption in the presence of network externalities. Journal of Political Economy, 94(4), 822-841.

Katz, M. L., \& Shapiro, C. (1994). Systems competition and network effects. Journal of Economic Perspectives, 8(2), 93-115.

Koh, T. K., \& Fichman, M. (2014). Multi-homing users' preferences for two-sided exchange networks. Management Information Systems Quarterly, 38(4), 977-996.

Lee, R. S. (2013). Vertical integration and exclusivity in platform and twosided markets. American Economic Review, 103(7), 2960-3000. 
Lestan, M., Urgo, J., \& Khoriaty, A. (2017). District0x Network - a Cooperative of Decentralized Marketplaces and Communities. https:// district0x.io/docs/district0x-whitepaper.pdf. Accessed 01.02.2018.

Lucas, H. C., \& Goh, J. M. (2009). Disruptive technology: How Kodak missed the digital photography revolution. The Journal of Strategic Information Systems, 18(1), 46-55.

Lusch, R. F., \& Nambisan, S. (2015). Service innovation: A servicedominant logic perspective. MIS Quarterly, 39(1), 155-175.

Majchrzak, A., \& Markus, M. L. (2013). Technology affordances and constraints in management information systems (Mis). In E. Kessler (Ed.), Encyclopedia of management theory (Vol. 1, p. 832). Thousand Oaks: SAGE Publications.

McIntyre, D. P., \& Srinivasan, A. (2017). Networks, platforms, and strategy: Emerging views and next steps. Strategic Management Journal, 38(1), 141-160.

Moore, J. F. (1993). Predators and prey: A new ecology of competition. Harvard Business Review, 71(3), 75-83.

Nambisan, S., Wright, M., \& Feldman, M. (2019). The digital transformation of innovation and entrepreneurship: Progress, challenges and key themes. Research Policy, 48(8), 1-9.

Oh, J., Koh, B., \& Raghunathan, S. (2015). Value appropriation between the platform provider and app developers in Mobile platform mediated networks. Journal of Information Technology, 30(3), 245-259.

Ondrus, J., Gannamaneni, A., \& Lyytinen, K. (2015). The impact of openness on the market potential of multi-sided platforms: A case study of Mobile payment platforms. Journal of Information Technology, 30(3), 260-275.

Orton, J. D., \& Weick, K. E. (1990). Loosely coupled systems: A reconceptualization. Academy of Management Review, 15(2), 203-223.

Parker, G., \& Van Alstyne, M. (2017). Innovation, openness, and platform control. Management Science, 64(7), 3015-3032.

Parker, G., Van Alstyne, M., \& Jiang, X. (2017). Platform ecosystems: How developers invert the firm. MIS Quarterly, 41(1), 255-266.

Riasanow, T., Burckhardt, F., Soto Setzke, D., Böhm, M., \& Krcmar, H. (2018a) The Generic Blockchain Ecosystem and Its Strategic Implications. In Proceedings of the Americas Conference of Information Systems, New Orleans, LA, United States.

Riasanow, T., Flötgen, R. J., Soto Setzke, D., Böhm, M., \& Krcmar, H. (2018b) The Generic Ecosystem and Innovation Patterns of the Digital Transformation in the Financial Industry. In Proceedings of the Pacific Asian Conference on Information Systems, Yokohama, Japan.

Rietveld, J., Schilling, M. A., \& Bellavitis, C. (2016) Reload and Relaunch: Value Creation and Value Capture in Platform-Based Markets. In Proceedings of the Academy of Management Annual Meeting, Anaheim, California.

Rochet, J.-C., \& Tirole, J. (2003). Platform competition in two-sided markets. Journal of the European Economic Association, 1(4), 990-1029.

SAP Partner Edge (2017). Geschäftschancen als Sap Partner. SAP SE, https://www.sap.com/germany/partner/become.html. Accessed 26. 03.2017.

SAP SE (2018). Transforming Elephant and Rhino Conservation. https:// discover.sap.com/best-run/en-us/customer-erp/index.html. Accessed 10 Mar 2019.

Satariano, A. Zhong, R., \& Wakabayashiand D. (2019) U.S. Tech Suppliers, Including Google, Restrict Dealings With Huawei After Trump Order, The New York Times, https://www.nytimes.com/ 2019/05/20/technology/google-android-huawei.html.

Schilling, M. A. (2002). Technology success and failure in winner-takeall markets: The impact of learning orientation, timing, and network externalities. Academy of Management Journal, 45(2), 387-398.

Schmalensee, R. (2000). Antitrust issues in Schumpeterian industries. American Economic Review, 90(2), 192-196.

Schreieck, M., Wiesche, M., Kude, T., \& Krcmar, H. (2019) Shifting to the Cloud - How Sap's Partners Cope with the Change. In
Proceedings of the Hawaii International Conference on System Sciences, Maui, Hawaii, USA

Sebastian, I. M., Ross, J. W., Beath, C., Mocker, M., Moloney, K. G., \& Fonstad, N. O. (2017). How Big Old Companies Navigate Digital Transformation. MIS Quarterly Executive, 16(3).

Selander, L., Henfridsson, O., \& Svahn, F. (2013). Capability search and redeem across digital ecosystems. Journal of Information Technology, 28(3), 183-197.

Song, P., Xue, L., Rai, A., \& Zhang, C. (2018). The ecosystem of software platform: A study of asymmetric cross-side network effects and platform governance. MIS Quarterly, 42(1), 121-142.

Steensma, H. K., \& Corley, K. G. (2000). On the performance of technology-sourcing partnerships: The interaction between partner interdependence and technology attributes. Academy of Management Journal, 43(6), 1045-1067.

Tan, T. C. F., Tan, B., \& Pan, S. L. (2016). Developing a leading digital multi-sided platform: Examining it affordances and competitive actions in Alibaba. Communication of the AIS, 38(1), 739-760.

Teece, D. J. (1986). Profiting from technological innovation: Implications for integration, collaboration, licensing and public policy. Research Policy, 15(6), 285-305.

Teece, D. J. (2018). Profiting from Innovation in the Digital Economy: Enabling Technologies, Standards, and Licensing Models in the Wireless World. Research Policy, 47(8).

Thies, F., Wessel, M., \& Benlian, A. (2016). Effects of social interaction dynamics on platforms. Journal of Management Information Systems, 33(3), 843-873.

Thomas, L. D. W., Autio, E., \& Gann, D. M. (2014). Architectural leverage: Putting platforms in context. Academy of Management Perspectives, 28(2), 198-219.

Tilson, D., Lyytinen, K., \& Sørensen, C. (2010). Research commentaryDigital infrastructures: The missing is research agenda. Information Systems Research, 21(4), 748-759.

Tiwana, A. (2014). Platform ecosystems: Aligning architecture, governance, and strategy. Burlington: Morgan Kaufmann.

Tiwana, A. (2015). Evolutionary competition in platform ecosystems. Information Systems Research, 18(1), 7047-7047.

Tiwana, A. (2018). Platform synergy: Architectural origins and competitive consequences. Information Systems Research, 29(4), 829-848.

Tiwana, A., Konsynski, B., \& Bush, A. A. (2010). Platform evolution: Coevolution of platform architecture, governance, and environmental dynamics. Information Systems Research, 21(4), 675-687.

U.S. Tech Suppliers, Including Google, Restrict Dealings with Huawei after Trump Order. (2019), The New York Times.

Urmetzer, F., Gill, A., \& Reed, N. (2018) Using Business Ecosystems Mapping to Generate New Competitive Value Propositions. In CIE 48, Auckland, NZ.

Wheelwright, S. C., \& Clark, K. B. (1992). Revolutionizing product development: Quantum leaps in speed, efficiency, and quality. New York: Simon and Schuster.

Wiedemann, A., Forsgren, N., Wiesche, M., Gewald, H., \& Krcmar, H. (2019). The DevOps phenomenon. Communications of the ACM, $62(8), 44-49$.

Xie, K., Liu, Z., Chen, L., Zhang, W., Liu, S., \& Chaudhry, S. S. (2018). Success factors and complex dynamics of Crowdfunding: An empirical research on Taobao platform in China. Electronic Markets, 29(2), 187-199.

Ye, H., \& Kankanhalli, A. (2018). User service innovation on Mobile phone platforms: Investigating impacts of Lead Userness, toolkit support, and design autonomy. MIS Quarterly, 42(1), 165-187.

Yoo, Y., Boland, R. J., Lyytinen, K., \& Majchrzak, A. (2012). Organizing for innovation in the digitized world. Organization Science, 23(5), 1398-1408.

Yoo, Y., Henfridsson, O., \& Lyytinen, K. (2010). Research commentary - The new organizing logic of digital innovation: An 
agenda for information systems research. Information Systems Research, 21(4), 724-735.

Zhu, F., \& Iansiti, M. (2019). Why Some Platforms Thrive and Others Don't. Harvard Business Review (1), 118-125.

Zhu, F., \& Liu, Q. (2018). Competing with Complementors: An empirical look at Amazon. Com. Strategic Management Journal, 39(10), $2618-2642$.
Zittrain, J. L. (2005). The generative internet. Harvard Law Review, 119, $1975-2039$.

Publisher's note Springer Nature remains neutral with regard to jurisdictional claims in published maps and institutional affiliations. 